\title{
Plantas de cobertura para o noroeste do estado de São Paulo
}

\author{
Cover crops for the northwest region from São Paulo State, Brazil
}

\author{
Wander Luis Barbosa Borges ${ }^{I^{*}}$ Rogério Soares de Freitas $^{\mathrm{I}}$ Gustavo Pavan Mateus $^{\mathrm{II}}$ \\ Marco Eustáquio de Sán ${ }^{I I I}$ Marlene Cristina Alves ${ }^{\text {IV }}$
}

\section{RESUMO}

O trabalho foi realizado com o objetivo de avaliar a produtividade de fitomassa de cinco plantas de cobertura utilizadas para produção de grãos, sementes e forragem, em diferentes densidades de semeadura, e da vegetação espontânea, na Região Noroeste do Estado de São Paulo. Os experimentos foram instalados em Votuporanga, SP e Selvíria, MS, em março de 2008 após o preparo convencional do solo. O delineamento experimental utilizado foi o de blocos casualizados com quatro repetições, utilizando as seguintes plantas de cobertura em diferentes densidades de semeadura que constituiram os tratamentos: Sorghum bicolor: 6, 7 e $8 \mathrm{~kg} \mathrm{ha}^{-1}$, Pennisetum americanum: 10, 15 e $20 \mathrm{~kg} \mathrm{ha}^{-1}$, Sorghum sudanense: 12, 15 e $18 \mathrm{~kg} \mathrm{ha}^{-1}$, hibrido de Sorghum bicolor com Sorghum sudanense: 8, 9 e $10 \mathrm{~kg} \mathrm{ha}^{-1}$, Urochloa ruziziensis: 8,12 e $16 \mathrm{~kg} \mathrm{ha}^{-1}$. Também se utilizou um tratamento controle com vegetação espontânea. Avaliou-se a fitomassa das diferentes coberturas no momento da colheita/corte das coberturas, na pré-semeadura e no florescimento das culturas da soja e do milho. A utilização de plantas de cobertura mostrouse mais benéfica que se deixar as áreas em pousio. Concluiu-se que as plantas de cobertura avaliadas mostraram-se como boas opções de plantas de cobertura para a região Noroeste do Estado de São Paulo. Além Disso, as diferentes densidades de semeadura de cada planta de cobertura não influenciaram na produtividade de fitomassa da mesma planta de cobertura.

Palavras-chave: semeadura direta, manejo sustentável do solo, matéria seca, densidade de semeadura.

\section{ABSTRACT}

This study was conducted to evaluate the productivity of biomass of five cover crops used for the production of grain, seeds and fodder in different sowing density per hectare, and of spontaneous vegetation for the northwest region of São Paulo State, Brazil. The experiments were installed in Votuporanga, SP, Brazil and Selviria, MS, Brazil in March 2008, after conventional tillage. The experimental design was a randomized complete block with four replications, using the following cover crops at different sowing density: Sorghum bicolor: 6, 7 and $8 \mathrm{~kg} \mathrm{ha}^{-1}$, Pennisetum americanum, 10, 15 and $20 \mathrm{~kg} \mathrm{ha}^{-1}$, Sorghum sudanense, 12, 15 and $18 \mathrm{~kg} \mathrm{ha}^{-1}$, hybrid of Sorghum bicolor with Sorghum sudanense: 8 , 9 and $10 \mathrm{~kg} \mathrm{ha}^{-1}$, Urochloa ruziziensis: 8,12 and $16 \mathrm{~kg} \mathrm{ha}^{-1}$. It was used a control treatment with spontaneous vegetation. The biomass of different toppings in harvesting/cutting of covers was evaluated, in the pre-sowing and flowering of soybean and corn. The use of cover crops proved more beneficial than leaving areas fallow. It was concluded that different cover crops evaluated showed to be good options as cover crops for the northwest region of São Paulo State and the different sowing density from each plant cover did not influence biomass productivity of the same plant coverage.

Key words: no tillage, sustainable soil management, dry matter, sowing density.

\section{INTRODUÇÃO}

Segundo SILVA et al. (2000), a adoção de sistemas conservacionistas de manejo do solo, dentre eles o sistema de semeadura direta e o uso de plantas de cobertura, constituem-se numa importante alternativa para assegurar a sustentabilidade do uso agrícola dos Latossolos no Brasil.

\footnotetext{
'Centro Avançado de Pesquisa Tecnológica do Agronegócio de Seringueira e Sistemas Agroflorestais, Instituto Agronômico (IAC), 15500-970, Votuporanga, SP, Brasil. E-mail: wanderborges@iac.sp.gov.br.*Autor para correspondência.

IIPolo Regional de Desenvolvimento Tecnológicos dos Agronegócios do Extremo Oeste, Agência Paulista de Tecnologia dos Agronegócios (APTA), Andradina, SP, Brasil.

IIIDepartamento de Fitotecnia, Tecnologia de Alimentos e Sócio-Economia, Universidade Estadual Paulista (UNESP), Ilha Solteira, SP, Brasil.

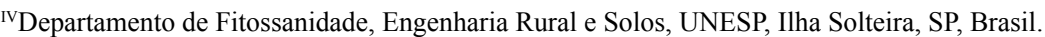


ALVARENGA et al. (2001) relataram que, na escolha das plantas de cobertura, é fato decisivo conhecer a sua adaptação à região e sua habilidade em crescer num ambiente menos favorável, uma vez que as culturas comerciais são estabelecidas nas épocas mais propícias. Além disso, deve-se levar em consideração a produtividade de fitomassa, disponibilidade de sementes, as condições do solo, rusticidade quanto à tolerância do déficit hídrico, a possibilidade de utilização comercial e o potencial dessas plantas serem hospedeiras de pragas e doenças. No entanto, a maior parte dos resultados de pesquisas feitas no Brasil é da Região Sul, onde as condições climáticas são muito diferentes das do cerrado brasileiro, particularmente, da região Noroeste do Estado de São Paulo. Para muitas regiões do Estado de São Paulo, ainda não há recomendação técnica das espécies mais adaptadas e, nas regiões de inverno seco, as dificuldades são maiores (TRABUCO, 2008).

O trabalho foi realizado com o objetivo de avaliar a produtividade de fitomassa de cinco plantas de cobertura utilizadas para produção de grãos, sementes e forragem, em diferentes densidades de semeadura, e da vegetação espontânea, na Região Noroeste do Estado de São Paulo.

\section{MATERIAL E MÉTODOS}

Os experimentos foram instalados em março de 2008, no Centro Avançado de Pesquisa Tecnológica do Agronegócio de Seringueira e Sistemas Agroflorestais, do Instituto Agronômico IAC, estabelecido no município de Votuporanga, SP, a $20^{\circ} 20^{\prime} \mathrm{S}$ de Latitude, $49^{\circ} 58^{\prime} \mathrm{W}$ de Longitude e $510 \mathrm{~m}$ de altitude, em um Latossolo Vermelho eutrófico de textura arenosa (EMBRAPA, 2006), e na Fazenda de Ensino, Pesquisa e Extensão da UNESP, Campus de Ilha Solteira, na Seção de Produção Vegetal, localizada no município de Selvíria, MS, a $13,9 \mathrm{~km}$ de Ilha Solteira, SP e com as mesmas características de solo e de clima, com coordenadas geográficas: Latitude $20^{\circ} 25^{\prime} 24^{\prime}$ 'S e Longitude 52²1'13'W, e altitude média de $335 \mathrm{~m}$, em um Latossolo Vermelho distroférrico típico de textura muito argilosa (Embrapa, 2006).

O solo foi preparado por meio de uma aração (arado de discos), em fevereiro de 2008, e duas gradagens (grade niveladora de discos), uma em fevereiro e outra no início de março, após a amostragem de solo para fins de fertilidade, na camada de $0-0,20 \mathrm{~m}$, realizada nos dois locais de cultivo.

As análises de solo apresentaram os seguintes resultados para Votuporanga e Selvíria, respectivamente: $\mathrm{P}$ (resina): 28 e $8 \mathrm{mg} \mathrm{dm}^{-3}$; $\mathrm{MO}$ :
14 e $19 \mathrm{mg} \mathrm{dm}^{-3} ; \mathrm{pH}\left(\mathrm{CaCl}_{2}\right): 5,2$ e 4,$2 ; \mathrm{K}: 3,8$ e $1,0 \mathrm{mmol}_{\mathrm{c}} \mathrm{dm}^{-3}$; $\mathrm{Ca}: 16$ e $6 \mathrm{mmol}_{\mathrm{c}} \mathrm{dm}^{-3} ; \mathrm{Mg}: 8 \mathrm{e}$ $6 \mathrm{mmol}_{\mathrm{c}} \mathrm{dm}^{-3} ; \mathrm{H}+\mathrm{Al}: 16$ e $47 \mathrm{mmol}_{\mathrm{c}} \mathrm{dm}^{-3} ; \mathrm{Al}: 0$ e $8 \mathrm{mmol}_{\mathrm{c}} \mathrm{dm}^{-3} ; \mathrm{S}_{-\mathrm{SO}_{4}}: 2$ e $3 \mathrm{mg} \mathrm{dm}^{-3}$; V: 63 e $22 \%$. Foi realizada calagem em Selvíria para elevação da saturação por bases a 70\%, pois, no ano seguinte, seria introduzida a cultura do milho na área, utilizando-se $3400 \mathrm{~kg} \mathrm{ha}^{-1}$ de calcário dolomítico, com PRNT de $85 \%$, incorporado com a segunda gradagem.

O clima da região Noroeste do Estado de São Paulo, segundo a classificação de Köppen, é do tipo Aw, definido como tropical úmido, com estação chuvosa no verão e seca no inverno, apresentando temperatura média anual de $24,5^{\circ} \mathrm{C}$, precipitação média anual de $1.232 \mathrm{~mm}$, umidade relativa média anual de $64,8 \%$ e déficit hídrico acentuado nos meses de junho a setembro (HERNANDEZ et al., 1995).

$\mathrm{O}$ delineamento experimental utilizado foi o de blocos casualizados com quatro repetições, utilizando-se cinco plantas de cobertura, com três diferentes densidades de semeadura de cada planta de cobertura e um tratamento controle com vegetação espontânea, totalizando dezesseis tratamentos, distribuídos ao acaso em parcelas de 2,7m de largura por $10 \mathrm{~m}$ de comprimento cada.

Foram utilizadas as seguintes plantas de cobertura, com as seguintes densidades de semeadura: sorgo granífero (Sorghum bicolor (L.) Moench) cultivar DKB 550, com 85\% de germinação: 6, 7 e $8 \mathrm{~kg}$ ha $^{-1}$; milheto (Pennisetum americanum (L.) Leek) cultivar BN 2, com $60 \%$ de germinação: 10, 15 e $20 \mathrm{~kg} \mathrm{ha}^{-1}$; capim sudão (Sorghum sudanense (Piper) Stapf) com valor cultural (VC) de 43,5\%, sendo corrigido para $100 \%$ : 12,15 e $18 \mathrm{~kg} \mathrm{ha}^{-1}$; híbrido de sorgo granífero (Sorghum bicolor (L.) Moench) com capim sudão (Sorghum sudanense (Piper) Stapf), cultivar Cover Crop, com germinação de $74 \%$, sendo acrescido 10\%: 8, 9 e 10kg ha-1 e Urochloa ruziziensis (Syn. Brachiaria ruziziensis) (cultivar comum), com VC de 50,7\%, sendo acrescido 10\%: 8, 12 e $16 \mathrm{~kg} \mathrm{ha}^{-1}$.

As diferentes densidades de semeadura adotadas foram baseadas em recomendações dos detentores das sementes e de diferentes trabalhos da literatura. Os espaçamentos entre linhas utilizados foram: S. bicolor: $0,45 \mathrm{~m}$; P. americanum: $0,225 \mathrm{~m}$; . sudanense: 0,225m; híbrido: $0,45 \mathrm{~m}$ e $\boldsymbol{U}$. ruziziensis: $0,225 \mathrm{~m}$.

O tratamento controle com vegetação espontânea era compostoprincipalmentepor Cenchrus echinatus L. e Digitaria horizontalis Willd, nos dois locais. As parcelas com o tratamento controle foram deixadas em pousio, após o preparo do solo e após o cultivo da cultura da soja. No entanto, receberam os mesmos tratos culturais das plantas de cobertura. 
As plantas de cobertura foram semeadas em 24/03/2008 em Votuporanga, mecanicamente, com semeadora de parcelas, e em 26/03/2008 em Selvíria, manualmente, abrindo-se sulcos de plantio com enxadas adaptadas, distribuindo as sementes no sulco, e depois tampando o sulco com enxadas adaptadas.

A semeadura das plantas de cobertura foi realizada após a adubação de semeadura, feita mecanicamente com semeadoras de grãos em toda a área, inclusive nas parcelas controle, utilizando-se o fertilizante formulado 08-28-16, nas doses de 170 e $315 \mathrm{~kg} \mathrm{ha}^{-1}$, em Votuporanga e Selvíria, respectivamente.

A adubação de cobertura foi realizada manualmente a lanço, em toda a área, inclusive nas parcelas controle. Foi utilizando sulfato de amônio, na dose de $185 \mathrm{~kg} \mathrm{ha}^{-1}$, aos 15 dias após a semeadura, e ureia, na dose de $170 \mathrm{~kg} \mathrm{ha}^{-1}$, aos 30 dias após a semeadura, em Votuporanga, e ureia, na dose de $65 \mathrm{~kg}$ $\mathrm{ha}^{-1}$, e cloreto de potássio, na dose de $35 \mathrm{~kg} \mathrm{ha}^{-1}$, aos 30 dias após a semeadura, em Selvíria.

Foi realizado o corte das panículas do $\mathrm{S}$. bicolor, do P. americanum e do S. sudanense, aos 115, 110 e 125 dias após a semeadura, respectivamente, simulando-se a colheita de grãos e/ou sementes. $\mathrm{O}$ híbrido e a $\boldsymbol{U}$. ruziziensis foram cortados a $0,20 \mathrm{~m}$ do solo e retirados da área, aos 95 e 145 dias após a semeadura, respectivamente, simulando-se ensilagem do híbrido e fenação da $\boldsymbol{U}$. ruziziensis. No tratamento controle, deixaram-se as plantas daninhas desenvolverem-se. No final do mês de agosto de 2008 , todas as parcelas foram roçadas. No início de novembro, realizou-se a primeira dessecação e vinte dias após realizou-se a segunda dessecação.

Após as dessecações, foi semeada a cultura da soja em sistema de semeadura direta. A colheita da soja foi realizada nos dias 08/04/2009 e 16/04/2009, em Selvíria e Votuporanga, respectivamente.

No segundo ano de estudo, a semeadura das plantas de cobertura foi realizada nos dias 13/04/2009, em Selvíria, e 18/05/2009, em Votuporanga, manualmente, sobre a palhada de soja cultivada anteriormente, nas mesmas parcelas utilizadas no ano anterior. As adubações foram novamente realizadas mecanicamente com semeadoras de grãos em todas as parcelas, utilizando-se o fertilizante formulado 08-28-16, nas doses de $300 \mathrm{~kg} \mathrm{ha}^{-1}$ e $275 \mathrm{~kg} \mathrm{ha}^{-1}$ em Votuporanga e Selvíria, respectivamente.

O manejo das plantas de cobertura e do tratamento controle foi o mesmo do ano anterior. As plantas de cobertura foram roçadas no final do mês de julho de 2009, em Selvíria, e em setembro, em Votuporanga.
Em Votuporanga, foi realizada a primeira dessecação das plantas de cobertura em 19/11/2009 e a segunda em 14/12/2009; em Selvíria, foi realizada a primeira dessecação em 04/11/2009 e a segunda em 25/11/2009. Após as dessecações, foi realizada a semeadura do milho, também em sistema de semeadura direta. Foram realizados todos os tratamentos fitossanitários necessários para o desenvolvimento adequado das culturas da soja e do milho e a calagem e as adubações foram realizadas conforme Boletim Técnico 100 (RAIJ et al., 1997).

As avaliações de fitomassa das coberturas foram realizadas no momento da colheita de grãos $(\boldsymbol{S}$. bicolor), da colheita de sementes (P. americanum e S. sudanense) e do corte (híbrido e $\boldsymbol{U}$. ruziziensis), e antes da roçada no tratamento controle, nos dois anos de estudo, na pré-semeadura da soja, em 28/10/2008 e 06/11/2008, no pleno florescimento da soja, em 19/02/2009 e 05/03/2009, na pré-semeadura do milho, em $04 / 11 / 2009$ e $16 / 11 / 2009$, e também no pleno florescimento do milho, em 21/03/2010 e 26/03/2010, em Selvíria e Votuporanga, respectivamente. Foram retiradas duas amostras de $0,5 \times 0,5 \mathrm{~m}$ por parcela, as quais foram acondicionadas em sacos de papel e levadas para secagem em estufa de ventilação forçada, regulada a $65-70^{\circ} \mathrm{C}$ por 72 horas. Nas avaliações realizadas no corte/colheita das coberturas e pré-semeadura da soja e pré-semeadura do milho, retirou-se a parte aérea das plantas de cobertura e, nas avaliações realizadas no pleno florescimento da soja e no pleno florescimento do milho, retiraram-se os resíduos das plantas de cobertura presentes sobre o solo.

Os dados foram submetidos ao teste $\mathrm{F}$ e realizado o teste de Tukey $(\mathrm{P}<0,05)$, para comparação das médias, com o uso do programa computacional ESTAT, desenvolvido pelo Departamento de Ciências Exatas da FCAV/UNESP/Jaboticabal (ESTAT, 1997). Os dados climáticos de precipitação pluvial (mm) e temperatura média mensal $\left({ }^{\circ} \mathrm{C}\right)$, em Votuporanga e Ilha Solteira, no período estudado, entre março de 2008 a abril de 2010, estão apresentados na figura 1 .

\section{RESULTADOS E DISCUSSÃO}

As diferentes coberturas diferiram entre si, em nível de 5\% de probabilidade pelo teste de Tukey, em relação à fitomassa, durante os três períodos avaliados, nos dois anos de estudo e nos dois locais. No entanto, as diferentes densidades de semeadura de cada planta de cobertura não propiciaram diferenças significativas, em nível de $5 \%$ de probabilidade pelo teste de Tukey, em relação à fitomassa da mesma planta de cobertura, durante os dois anos de estudo e nos dois locais, conforme tabelas 1 e 2 . Por outro 


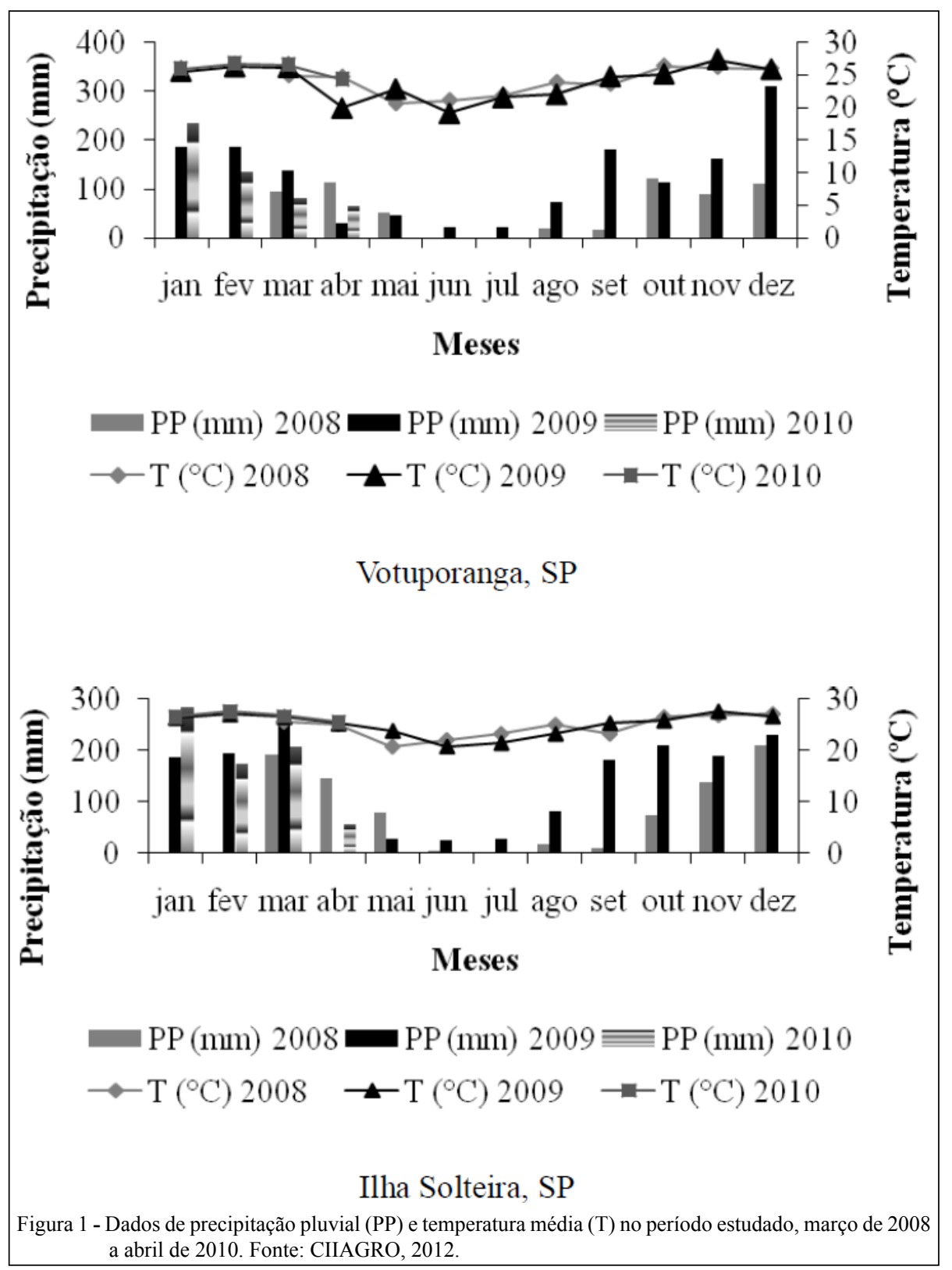

lado, houve uma tendência de maior produtividade de fitomassa com a utilização das densidades intermediárias, com o $\boldsymbol{S}$. sudanense, em Selvíria, e a $\boldsymbol{U}$. ruziziensis, em Votuporanga, no primeiro ano de estudo, e com o híbrido, em Votuporanga, e a $\boldsymbol{U}$. ruziziensis, em Selvíria, no segundo ano de estudo.

Em Votuporanga, no primeiro ano de estudo, no momento da pré-semeadura da soja, todas as plantas de cobertura, nas três densidades de semeadura, apresentaram produtividades de fitomassa superiores às do segundo ano, que teve uma redução na pluviosidade acumulada nos meses de abril a junho de $41,56 \%$, conforme figura 1 .
A densidade de semeadura de $12 \mathrm{~kg} \mathrm{ha}^{-1}$ da $\boldsymbol{U}$. ruziziensis propiciou a melhor estabilidade de permanência de fitomassa sobre o solo nos dois anos de estudo e nos dois locais, com a segunda maior quantidade de fitomassa no momento do florescimento da cultura da soja e a maior quantidade de fitomassa no momento do florescimento do milho, mostrando a excelente capacidade de rebrota após o corte para utilização como feno e lenta decomposição, mantendo o solo coberto por maior período de tempo.

Nos dois anos de estudo e nos dois locais, o tratamento controle, no momento da roçada, apresentou fitomassa inferior a $3,5 \mathrm{Mg} \mathrm{ha}^{-1}$, valores 
Tabela 1 - Fitomassa das plantas de cobertura e do tratamento controle, nos municípios de Votuporanga, SP e Selvíria, MS, no momento do corte/colheita das coberturas (1) e na pré-semeadura (2) e florescimento da cultura da soja (3).

\begin{tabular}{|c|c|c|c|c|c|c|c|c|c|c|c|c|c|}
\hline \multirow{2}{*}{$\begin{array}{l}\text { Coberturas } \\
\text { S. bicolor }\end{array}$} & \multirow{2}{*}{$\begin{array}{c}* \\
\\
6\end{array}$} & \multicolumn{2}{|r|}{1} & \multicolumn{2}{|c|}{2} & \multicolumn{2}{|c|}{3} & \multicolumn{6}{|c|}{$\begin{array}{ccc} & & \\
1 & 2 & 3\end{array}$} \\
\hline & & 14,0 & bcd & 3,5 & $\mathrm{bc}$ & 2,1 & $\mathrm{bc}$ & 11,9 & $a b c$ & 2,4 & & 1,9 & ef \\
\hline S. bicolor & 7 & 16,2 & $\mathrm{bc}$ & 3,8 & $\mathrm{bc}$ & 1,7 & $\mathrm{c}$ & 12,6 & $a b$ & 3,4 & cde & 2,2 & ef \\
\hline S. bicolor & 8 & 15,3 & bcd & 4,5 & $a b c$ & 2,5 & $\mathrm{bc}$ & 11,9 & $a b c$ & 3,0 & cde & 2,3 & def \\
\hline P. americanum & 10 & 7,4 & efg & 2,9 & $\mathrm{c}$ & 3,2 & $\mathrm{abc}$ & 6,3 & cde & 2,7 & cde & 2,3 & def \\
\hline P. americanum & 15 & 6,3 & $\mathrm{fg}$ & 3,5 & $\mathrm{bc}$ & 3,5 & $\mathrm{abc}$ & 6,2 & cde & 3,3 & cde & 2,0 & ef \\
\hline P. americanum & 20 & 7,4 & efg & 3,6 & $\mathrm{bc}$ & 2,5 & $\mathrm{bc}$ & 5,8 & de & 2,5 & de & 2,8 & cdef \\
\hline S. sudanense & 12 & 12,6 & cde & 6,9 & $\mathrm{ab}$ & 4,8 & $\mathrm{a}$ & 6,9 & bcde & 7,7 & $\mathrm{ab}$ & 6,2 & $\mathrm{a}$ \\
\hline S. sudanense & 15 & 12,0 & cdef & 6,3 & $\mathrm{abc}$ & 3,6 & $\mathrm{abc}$ & 6,8 & bcde & 7,5 & $\mathrm{ab}$ & 4,7 & $\mathrm{abc}$ \\
\hline S. sudanense & 18 & 11,2 & cdef & 7,9 & $\mathrm{a}$ & 3,7 & $\mathrm{abc}$ & 6,7 & cde & 8,8 & $\mathrm{a}$ & 5,2 & $\mathrm{ab}$ \\
\hline Híbrido & 8 & 19,8 & $\mathrm{ab}$ & 6,3 & $\mathrm{abc}$ & 2,6 & $\mathrm{bc}$ & 14,8 & $\mathrm{a}$ & 1,5 & e & 2,0 & ef \\
\hline Híbrido & 9 & 23,8 & $\mathrm{a}$ & 7,6 & $\mathrm{a}$ & 2,6 & $\mathrm{bc}$ & 13,3 & a & 0,9 & e & 1,6 & ef \\
\hline Híbrido & 10 & 23,0 & $\mathrm{a}$ & 5,5 & $\mathrm{abc}$ & 1,8 & $\mathrm{bc}$ & 15,4 & a & 1,2 & $\mathrm{e}$ & 1,2 & $\mathrm{f}$ \\
\hline U. ruziziensis & 8 & 10,8 & cdef & 4,7 & $\mathrm{abc}$ & 3,3 & $\mathrm{abc}$ & 11,1 & abcd & 5,7 & $\mathrm{bc}$ & 4,3 & abcd \\
\hline U. ruziziensis & 12 & 10,2 & cdef & 5,5 & $\mathrm{abc}$ & 3,8 & $\mathrm{ab}$ & 11,3 & abcd & 5,7 & $\mathrm{bc}$ & 5,8 & $\mathrm{a}$ \\
\hline U. ruziziensis & 16 & 9,4 & def & 5,5 & $a b c$ & 3,7 & $a b c$ & 9,8 & abcd & 5,1 & bcd & 4,8 & $a b c$ \\
\hline Controle & - & 2,5 & $\mathrm{~g}$ & 3,6 & $\mathrm{bc}$ & 3,7 & $\mathrm{abc}$ & 3,4 & $\mathrm{e}$ & 3,4 & cde & 3,6 & bcde \\
\hline DMS & & &, 081 & & 58 & & 17 & & & 3,0 & & & \\
\hline CV (\%) & & & 8,81 & & 46 & & 56 & & & 29 & & & \\
\hline
\end{tabular}

Médias seguidas de mesma letra na coluna não diferem entre si pelo teste de Tukey a 5\% probabilidade.

*densidades de semeadura $\left(\mathrm{kg} \mathrm{ha}^{-1}\right)$.

semelhantes ao constatado por NUNES et al. (2006), que obtiveram produtividade de $3,6 \mathrm{Mg} \mathrm{ha}^{-1}$ para a área em pousio. Por outro lado, todas as plantas de coberturas, com as diferentes densidades de semeadura, nomomento do corte/colheita, propiciaram quantidades de fitomassa superior a $5,7 \mathrm{Mg}$ ha $^{-1}$, mostrando rápido desenvolvimento vegetativo, uma das características desejáveis às plantas de cobertura.

A fitomassa da densidade de semeadura de $15 \mathrm{~kg} \mathrm{ha}^{-1}$ do $\boldsymbol{P}$. americanum, no momento da colheita, foi superior à encontrada por SODRÉ FILHO et al. (2004) e TORRES et al. (2005), no ano agrícola 2001/02, que constataram 1,9 e $3,6 \mathrm{Mg} \mathrm{ha}^{-1}$, respectivamente, e inferior à encontrada por BOER et al. (2008), TORRES et al. (2005), no ano agrícola 2000/01, e GUIMARÃES (2000), que obtiveram $10,8,10,3$ e 7,3 $\mathrm{Mg} \mathrm{ha}^{-1}$, respectivamente.

Em Selvíria, no primeiro ano de estudo, a fitomassa das três densidades de semeadura do S. bicolor, no momento da colheita, variou de 11,9 a $12,6 \mathrm{Mg} \mathrm{ha}^{-1}$, valor semelhante ao encontrado por BORDIN et al. (2003), que foi de $12,7 \mathrm{Mg} \mathrm{ha}^{-1}$ de matéria seca aos 70 dias após semeadura. Já o híbrido, provavelmente devido às condições climáticas desfavoráveis, com ausência de pluviosidade no mês de julho, conforme figura 1, e altura de corte muito próxima ao solo, teve seu rebrote comprometido após o corte para ensilagem e apresentou uma quantidade de fitomassa inferior a $1,5 \mathrm{Mg} \mathrm{ha}^{-1}$.

As fitomassas das plantas de cobertura, no momento do corte/colheita, no segundo ano de estudo, em Selvíria, foram superiores às do primeiro ano de estudo, no mesmo período de avaliação, concordando com FABIAN (2009), que verificou, no ano de 2006, produções de matéria seca das coberturas inferiores às de 2005. O autor citou que esses resultados podem ser explicados pela má distribuição de chuvas no período de maio a setembro de 2006, fato semelhante ao ocorrido em Selvíria no primeiro ano de estudo, conforme figura 1.

No momento da pré-semeadura e no florescimento da cultura do milho, nos dois locais, as três densidades de semeadura do P. americanum apresentaram as menores quantidades de fitomassa. Isso se deu devido à redução da área foliar, causada pela alta intensidade de ferrugem causada pelo fungo Puccinia substriata var. penicillariae, o que prejudicou o desenvolvimento da cultura após a roçada.

Analisando a fitomassa acumulada pelas coberturas, em cada ano de estudo, somando-se a fitomassa obtida antes da roçada à fitomassa obtida 
Tabela 2 - Fitomassa das plantas de cobertura e do tratamento controle, nos municípios de Votuporanga, SP, e Selvíria, MS, no momento do corte/colheita das coberturas (1) e na pré-semeadura (2) e florescimento da cultura do milho (3).

\begin{tabular}{|c|c|c|c|c|c|c|c|c|c|c|c|c|c|}
\hline \multirow{2}{*}{$\begin{array}{l}\text { Coberturas } \\
\text { S. bicolor }\end{array}$} & \multirow{2}{*}{$\begin{array}{l}* \\
\\
6\end{array}$} & \multicolumn{2}{|c|}{1} & \multicolumn{2}{|c|}{2} & \multicolumn{2}{|c|}{3} & \multicolumn{2}{|c|}{1} & \multicolumn{2}{|c|}{2} & \multicolumn{2}{|c|}{3} \\
\hline & & 7,5 & $\mathrm{de}$ & 3,0 & $\mathrm{~cd}$ & 0,9 & ghi & 17,3 & $a b c$ & 5,4 & $\mathrm{a}$ & 1,6 & def \\
\hline S. bicolor & 7 & 6,9 & de & 2,6 & cde & 1,1 & ghi & 15,6 & $a b c$ & 6,1 & $\mathrm{a}$ & 1,7 & def \\
\hline S. bicolor & 8 & 7,4 & $\mathrm{de}$ & 3,0 & $\mathrm{~cd}$ & 1,3 & fgh & 15,7 & $a b c$ & 5,9 & $\mathrm{a}$ & 1,6 & def \\
\hline P. americanum & 10 & 7,9 & cde & 0,4 & $\mathrm{e}$ & 0,2 & hi & 10,4 & $\mathrm{~cd}$ & 1,2 & $\mathrm{~b}$ & 0,7 & ef \\
\hline P. americanum & 15 & 8,7 & cde & 0,4 & $\mathrm{e}$ & 0,3 & hi & 11,3 & bcd & 1,1 & $\mathrm{~b}$ & 0,3 & $\mathrm{f}$ \\
\hline P. americanum & 20 & 8,5 & cde & 0,5 & de & 0,1 & $\mathrm{i}$ & 9,9 & $\mathrm{~cd}$ & 1,7 & $\mathrm{~b}$ & 0,7 & ef \\
\hline S. sudanense & 12 & 16,4 & $\mathrm{a}$ & 5,8 & $\mathrm{ab}$ & 2,6 & bcde & 17,1 & $a b c$ & 4,6 & $a b$ & 3,2 & bcd \\
\hline S. sudanense & 15 & 16,9 & $\mathrm{a}$ & 4,6 & $a b c$ & 2,3 & def & 24,4 & $\mathrm{a}$ & 5,9 & $\mathrm{a}$ & 3,3 & bcd \\
\hline S. sudanense & 18 & 15,1 & $\mathrm{ab}$ & 6,9 & $\mathrm{a}$ & 2,9 & bcd & 22,9 & $\mathrm{a}$ & 5,3 & $\mathrm{a}$ & 2,7 & cdef \\
\hline Híbrido & 8 & 13,7 & $a b c$ & 3,7 & $\mathrm{bc}$ & 1,5 & $\mathrm{fg}$ & 21,9 & $a b$ & 6,4 & $\mathrm{a}$ & 2,7 & cdef \\
\hline Híbrido & 9 & 9,9 & bcd & 4,3 & $\mathrm{bc}$ & 1,8 & efg & 25,1 & $\mathrm{a}$ & 5,3 & $\mathrm{a}$ & 3,0 & bcde \\
\hline Híbrido & 10 & 10,8 & abcd & 3,7 & $\mathrm{bc}$ & 1,7 & efg & 22,4 & $\mathrm{ab}$ & 5,4 & $\mathrm{a}$ & 2,3 & cdef \\
\hline U. ruziziensis & 8 & 8,4 & cde & 2,5 & cde & 3,4 & $a b c$ & 16,4 & $\mathrm{abc}$ & 6,5 & $\mathrm{a}$ & 4,6 & $a b c$ \\
\hline U. ruziziensis & 12 & 9,1 & bcd & 2,9 & cde & 4,3 & $\mathrm{a}$ & 19,1 & $a b c$ & 5,5 & $\mathrm{a}$ & 5,9 & $\mathrm{a}$ \\
\hline U. ruziziensis & 16 & 8,8 & cde & 2,8 & cde & 3,7 & $\mathrm{ab}$ & 17,7 & $\mathrm{abc}$ & 6,0 & $\mathrm{a}$ & 5,3 & $\mathrm{ab}$ \\
\hline Controle & - & 2,8 & $\mathrm{e}$ & 2,2 & cde & 2,3 & cdef & 3,0 & $\mathrm{~d}$ & 3,9 & $\mathrm{ab}$ & 1,9 & def \\
\hline DMS & & \multicolumn{2}{|c|}{6,098} & \multicolumn{2}{|c|}{2,535} & \multicolumn{2}{|c|}{1,087} & \multicolumn{2}{|c|}{11,376} & \multicolumn{2}{|c|}{3,585} & \multicolumn{2}{|c|}{2,375} \\
\hline CV (\%) & & \multicolumn{2}{|c|}{23,96} & \multicolumn{2}{|c|}{32,26} & \multicolumn{2}{|c|}{22,2} & & 28 & \multicolumn{2}{|c|}{29,39} & \multicolumn{2}{|c|}{35,88} \\
\hline
\end{tabular}

Médias seguidas de mesma letra na coluna não diferem entre si pelo teste de Tukey a 5\% probabilidade.

* densidades de semeadura $\left(\mathrm{kg} \mathrm{ha}^{-1}\right)$.

na pré-semeadura da soja, no primeiro ano, e na pré-semeadura do milho, no segundo ano, verificase que, nos dois anos de estudo e nos dois locais, as três densidades de semeadura do $\boldsymbol{S}$. sudanense e a densidade de semeadura de 6 e $8 \mathrm{~kg} \mathrm{ha}^{-1}$ do $\boldsymbol{S}$. bicolor propiciaram acúmulo de fitomassa superior a $10,0 \mathrm{Mg}$ ha $^{-1}$, quantidade mínima de matéria seca acumulada por ano, em região de cerrado, para manutenção adequada do sistema de semeadura direta, segundo CORDEIRO (1999) e AMADO (2000). Por outro lado, o tratamento controle com a mesma adubação das plantas de coberturas, no entanto, sem produzir grãos, sementes ou forragem, acumulou quantidade inferior a 7,0 Mg ha ${ }^{-1}$. Esse fato evidencia que a utilização de áreas de pousio para o sistema de semeadura direta pode não trazer ao agricultor os vários benefícios advindos da utilização desta prática, além de dificultar o manejo de plantas daninhas nas culturas comerciais, pelo aumento do banco de sementes das plantas daninhas.

\section{CONCLUSÃO}

As plantas de cobertura avaliadas mostraram-se como boas opções de plantas de cobertura para a região Noroeste do Estado de São Paulo e as diferentes densidades de semeadura de cada planta de cobertura não influenciaram na produtividade de fitomassa da mesma planta de cobertura.

\section{AGRADECIMENTOS}

Agradecemos a Fundação Agricultura Sustentável (AGRISUS) pelo apoio financeiro para instalação e condução da pesquisa científica - Processo Agrisus n ${ }^{\circ} 482 / 08$.

Agradecemos também ao Prof. Dr. Walter Veriano Valério Filho, do Departamento de Matemática da Faculdade de Engenharia de Ilha Solteira (FEIS), Universidade Estadual Paulista (UNESP), pela colaboração nas análises estatísticas, e a todos os funcionários do Centro Avançado de Pesquisa Tecnológica do Agronegócio de Seringueira e Sistemas Agroflorestais, Instituto Agronômico (IAC), e da Fazenda de Ensino Pesquisa e Extensão da FEIS/UNESP, pelo apoio na instalação e condução dos campos experimentais.

\section{REFERÊNCIAS}

ALVARENGA, R.C. et al. Plantas de cobertura de solo para sistema plantio direto. Informe Agropecuário, v.22, n.208, p.25-36, 2001.

AMADO, T.J.C. Manejo da palha, dinâmica da matéria orgânica e ciclagem de nutrientes em plantio direto. In: ENCONTRO NACIONAL DE PLANTIO DIRETO NA PALHA, 7., 2000, Foz do Iguaçu. Resumos... Ponta Grossa: FEBRAPDP, 2000. p.105-111. 
BOER, C.A. et al. Biomassa, decomposição e cobertura do solo ocasionada por resíduos culturais de três espécies vegetais na região Centro-Oeste do Brasil. Revista Brasileira de Ciência do Solo, v.32, n.2, p.843-851, 2008. Disponível em: $<$ http://dx.doi. org/10.1590/S0100-06832008000200038>. Acesso em: 20 mai. 2008. doi: 10.1590/S0100-06832008000200038.

BORDIN, L. et al. Sucessão de cultivo de feijão-arroz com doses de adubação nitrogenada após adubação verde, em semeadura direta. Bragantia, v.62, n.3, p.417-428, 2003. Disponível em: $<\mathrm{http}$ //dx.doi.org/10.1590/S0006-87052003000300008>. Acesso em: 20 mai. 2008. doi: 10.1590/S0006-87052003000300008.

CENTRO INTEGRADO DE INFORMAÇÕES AGROMETEOROLÓGICAS (CIIAGRO). Resenha: Votuporanga e Ilha Solteira no período de 01/03/2008 até 31/04/2010. São Paulo, 2012. Acesso em 20 maio, 2012 Online. Disponível em: <http://www.ciiagro.sp.gov.br/ ciiagroonline/Listagens/Resenha/LResenhaLocal.asp $>$.

CORDEIRO, L. A. M. Importância da rotação de culturas para o sistema plantio direto. In: SEMINÁRIO SOBRE O SISTEMA PLANTIO DIRETO NA UFV, 2., 1999, Viçosa, MG. Anais... Viçosa, MG: UFV, 1999. p.165-190.

EMPRESA BRASILEIRA DE PESQUISA AGROPECUÁRIA (EMBRAPA). Centro Nacional de Pesquisa de Solos. Sistema brasileiro de classificação de solos. Rio de Janeiro, 2006. 306p.

ESTAT - Sistema para análises estatísticas. (V.2.0). Jaboticabal: Polo Computacional/Departamento de Ciências Exatas/UNESPFCAV, Campus de Jaboticabal, [s.d.]. 1997.

FABIAN, A.J. Plantas de cobertura: efeito nos atributos do solo e na produtividade de milho e soja em rotação. 2009. 83f. Tese (Doutorado em Agronomia/Produção Vegetal) - Universidade Estadual Paulista, Jaboticabal, SP.

GUIMARÃES, G.L. Efeitos de culturas de inverno e do pousio na rotação de culturas de soja e do milho em sistema de plantio direto. 2000. 108f. Dissertação(Mestrado em Agronomia/Sistemas de Produção) - Universidade Estadual Paulista, Ilha Solteira, SP. HERNANDEZ, F.B.T. et al. Software HIDRISA e o balanço hídrico de Ilha Solteira. Ilha Solteira: UNESP/FEIS, 1995. 45p. (Área de Hidráulica e Irrigação. Série Irrigação, 1).

NUNES, U.R. et al. Produção de palhada de plantas de cobertura e rendimento do feijão em plantio direto. Pesquisa Agropecuária Brasileira, v.41, n.6, p.943-948, 2006. Disponível em: <http:/ dx.doi.org/10.1590/S0100-204X2006000600007>. Acesso em: 20 mai. 2008. doi: 10.1590/S0100-204X2006000600007.

RAIJ, B. van. et al. (Eds.). Recomendações de adubação e calagem para o Estado de São Paulo. 2.ed. Campinas: IAC, 1997. p.56-59. (Boletim Técnico, 100).

SILVA, M.L.N. et al. Sistemas de manejo e qualidade estrutural de Latossolo Roxo. Pesquisa Agropecuária Brasileira, v.35, n.12, p.2485-2492, 2000. Disponível em: <http://dx.doi.org/10.1590/ S0100-204X2000001200019>. Acesso em: 20 mai. 2008. doi: 10.1590/S0100-204X2000001200019.

SODRÉ FILHO, J. et al. Fitomassa e cobertura do solo de culturas de sucessão ao milho na Região do Cerrado. Pesquisa Agropecuária Brasileira, v.39, n.4, p.327-334, 2004. Disponível em: $<$ http://dx.doi.org/10.1590/S0100-204X2004000400005>. Acesso em: 20 mai. 2008. doi: 10.1590/S0100-204X2004000400005.

TORRES, J.L.R. et al. Decomposição e liberação de nitrogênio de resíduos culturais de plantas de cobertura em um solo de cerrado. Revista Brasileira de Ciência do Solo, v.29, n.4, p.609618, 2005. Disponível em: <http://dx.doi.org/10.1590/S010006832005000400013>. Acesso em: 20 mai. 2008. doi: 10.1590/ S0100-06832005000400013.

TRABUCO, M. Produção de milho em plantio direto após plantas de cobertura. 2008. 54f. Dissertação (Mestrado em Agronomia/Produção Vegetal) - Universidade Estadual Paulista, Jaboticabal, SP. 